\title{
UPAYA PENINGKATAN CAKUPAN ASI EKSKLUSIF DAN INISIASI MENYUSU DINI (IMD)
}

\section{THE IMPROVEMENT EFFORTS OF EXCLUSIVE BREASTFEEDING AND EARLY INITIATION OF BREASTFEEDING}

\author{
Mina Yumei Santi \\ Jurusan Kebidanan Politeknik Kesehatan (Poltekkes) \\ Kementerian Kesehatan Yogyakarta
}

\begin{abstract}
ABSTRAK
Angka kematian bayi menurut Survei Kesehatan Demografi Indonesia pada tahun 2012 masih cukup tinggi yaitu 32 per 1.000 kelahiran hidup dan di bawah lima tahun tingkat kematian 40 per 1.000 kelahiran hidup. Upaya untuk mencegah kematian bayi adalah dengan menyusui segera setelah kelahiran atau biasa disebut inisiasi dini menyusui dan pemberian ASI eksklusif. Cakupan pemberian ASI eksklusif nasional pada 2014 sebesar 52,3\% masih di bawah target nasional sebesar 80\%. Tujuan dari penelitian ini adalah untuk menemukan upaya untuk memperbaiki cakupan pemberian ASI eksklusif dan inisiasi awal menyusui. Upaya yang bisa dilakukan adalah memberdayakan masyarakat melalui Mother Support Group, mensosialisasikan Peraturan Pemerintah No. 33 tahun 2012 tentang pemberian ASI eksklusif dan konseling menyusui memberikan kekuasaan. Pemerintah daerah disarankan untuk menyusun peraturan daerah yang mendukung pelaksanaan program inisiasi menyusui dini dan pemberian ASI eksklusif sehingga memiliki kekuatan hukum yang mengikat bagi semua pihak yang terlibat serta melakukan promosi, pemantauan, evaluasi dan pengawasan pelaksanaan dan Tercapainya program ASI eksklusif. Kata kunci: pemberian ASI eksklusif, inisiasi menyusui dini, konselor bidan.
\end{abstract}

\begin{abstract}
Infant mortality rate by Indonesia Demographic Health Survey in 2012 is still quite high at 32 per 1,000 live births and under five year mortality rates of 40 per 1,000 live births. An effort to prevent infant mortality is by breastfeeding soon after birth or so-called early initiation of breastfeeding and exclusive breastfeeding. Coverage of exclusive breastfeeding nationwide in 2014 amounted to $52.3 \%$ is still below the national target of $80 \%$. The aim of this research was to find the efforts to improve the coverage of exclusive breastfeeding and the early initiation of breastfeeding. The Efforts that can do are empowering people through Mother Support Group, socialize the Government Regulation No. 33 of 2012 on exclusive breastfeeding and breastfeeding counselor provides power. The local government is advised to draw up local regulations that support the implementation of the early initiation of breastfeeding program and exclusive breastfeeding so as to have binding legal force for all parties involved as well as to conduct promotion, monitoring, evaluating and supervising the implementation and achievement of the program exclusive breastfeeding.

Keywords:exclusive breastfeeding, early initiation of breastfeeding, midwife counselor.

\section{PENDAHULUAN}

Berdasarkan hasil Survei Demografi

dan Kesehatan Indonesia (SDKI) tahun

2012, Angka Kematian Neonatus (AKN)

pada tahun 2012 sebesar 19 per 1.000

kelahiran hidup. Angka ini sama dengan

AKN berdasarkan SDKI tahun 2007 dan

hanya menurun 1 poin dibanding SDKI

tahun 2002-2003 yaitu 20 per 1.000

kelahiran hidup. Angka Kematian Bayi di

Indonesia menurut Survei Demografi

Kesehatan Indonesia (SDKI) tahun 2012
\end{abstract}


masih cukup tinggi yaitu 32 per 1.000 kelahiran hidup dan angka kematian balita 40 per 1.000 kelahiran hidup (Kementerian Kesehatan, 2015). Walaupun angka ini memang menunjukkan penurunan dibandingkan dengan angka tahun 2007 yaitu 34 per 1.000 kelahiran hidup tetapi penurunan ini masih jauh dari target tujuan pembangunan milenium atau Millenium Development Goals (MDGs) tahun 2015 karena diharapkan angka kematian bayi dapat turun menjadi 23 per 1.000 kelahiran hidup dan angka kematian balita turun menjadi 32 per 1.000 kelahiran hidup (Minarto, 2011).

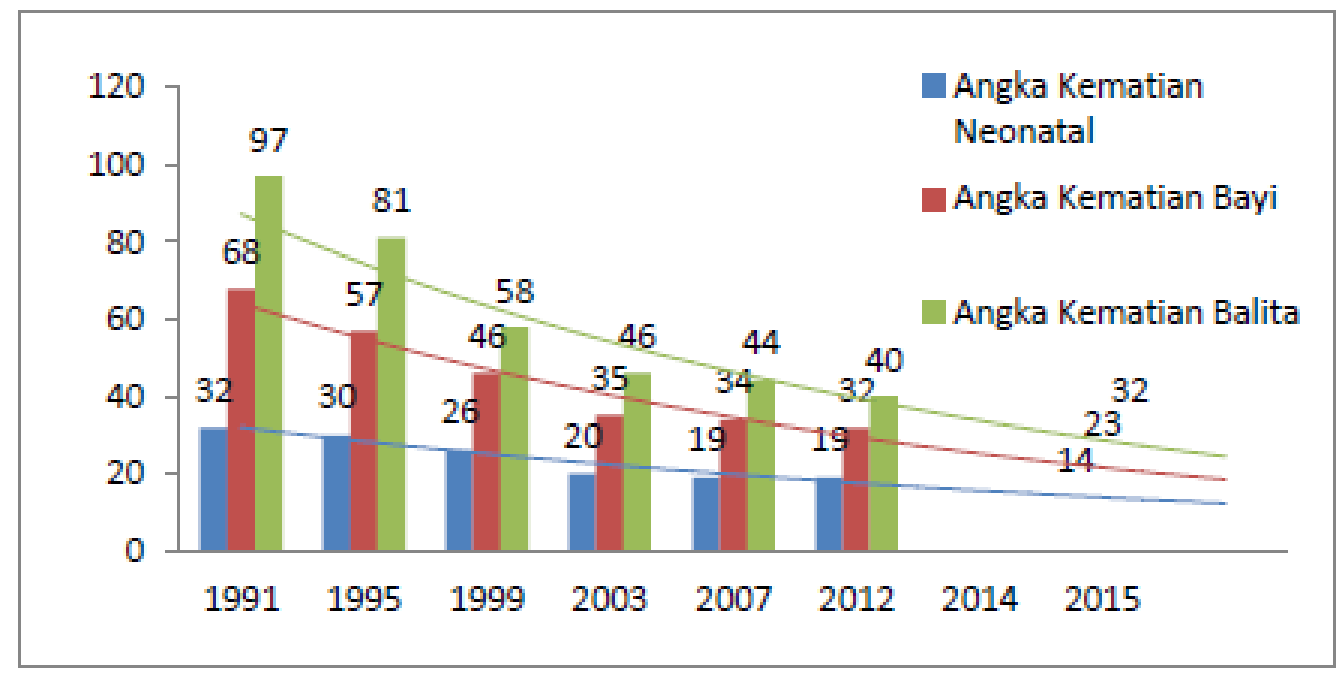

Sumber: Ditjen Gizi dan KIA, Kemenkes RI, 2015

Gambar 1. Tren angka kematian neonatal, bayi, dan balita.

Salah satu upaya yang dapat dilakukan untuk mencegah terjadinya kematian balita adalah dengan pemberian Air Susu Ibu (ASI) segera setelah lahir atau biasa disebut Inisiasi Menyusu Dini (IMD) serta pemberian ASI eksklusif. Hal ini didukung oleh pernyataan United Nations Childrens Fund (UNICEF), bahwa sebanyak 30.000 kematian bayi di Indonesia dan 10 juta kematian anak balita di dunia pada tiap tahunnya bisa dicegah melalui pemberian
ASI secara eksklusif selama enam bulan sejak tanggal kelahirannya, tanpa harus memberikan makanan serta minuman tambahan kepada bayi. Berdasarkan penelitian WHO (2000), di enam negara berkembang, risiko kematian bayi antara usia 9-12 bulan meningkat $40 \%$ jika bayi tersebut tidak disusui. Untuk bayi berusia di bawah dua bulan, angka kematian ini meningkat menjadi $480 \%$, sekitar $40 \%$ kematian balita terjadi satu bulan pertama 
kehidupan bayi. IMD dapat mengurangi $22 \%$ kematian bayi 28 hari, berarti IMD mengurangi kematian balita $8,8 \%$. Penelitian yang dilakukan Lancet (2003) mendapatkan bahwa dengan menyusui eksklusif selama 6 bulan dan tetap diberi ASI sampai 11 bulan saja serta pemberian makanan pendamping ASI pada usia enam bulan dapat menurunkan kematian balita sebanyak 13\% (Roesli, 2008). Edmond et al (2006) menyatakan bahwa $16 \%$ kematian neonatal dapat dicegah jika bayi disusui sejak hari pertama kelahirannya dan jika bayi menyusu dalam 1 jam pertama maka akan menurunkan angka kematian sebesar $22 \%$.

Inisiasi Menyusu Dini (IMD) mulai diperkenalkan di Indonesia pada tahun 2007 (Tasya, 2011) yaitu bayi mulai menyusu sendiri segera setelah lahir dan dilakukan dengan cara meletakkan bayi yang baru lahir secara tengkurap di dada atau perut ibu sehingga kulit bayi melekat pada kulit ibu (Peraturan Pemerintah No. 33 Tahun 2012). ASI eksklusif adalah pemberian hanya ASI saja tanpa makanan dan minuman lain. ASI eksklusif dianjurkan sampai 6 bulan pertama kehidupan bayi (World Health Organization, 2007). Dengan begitu selama 6 bulan pertama kehidupannya, seorang bayi hanya mendapatkan ASI eksklusif saja dan ini diajurkan oleh badan kesehatan dunia atau World Health Organization (WHO) setelah sebelumnya pemberian ASI eksklusif dinyatakan diberikan sampai bayi berusia 4 (empat) bulan.

Secara nasional cakupan pemberian ASI eksklusif di Indonesia berfluktuasi dan menunjukkan kecenderungan menurun selama 3 tahun terakhir. Cakupan pemberian ASI eksklusif pada bayi 0-6 bulan turun dari $62,2 \%$ tahun 2007 menjadi 56,2\% pada tahun 2008. Sedangkan cakupan pemberian ASI eksklusif pada bayi sampai 6 bulan turun dari 28,6\% pada tahun 2007 menjadi 24,3\% pada tahun 2008 (Minarto, 2011). Angka ini semakin menurun pada tahun 2010 karena data dari Riset Kesehatan Dasar (Riskesdas) tahun 2010 menunjukkan bahwa pemberian ASI eksklusif sampai dengan 6 bulan hanya 15,3\% (Bararah, 2011), persentase inisiasi menyusu dini kurang dari satu jam setelah bayi lahir adalah 29,3\% (Balitbang Kesehatan Kemenkes, 2010).

Hal ini menjadi suatu keprihatinan karena salah satu sasaran keluaran Pembinaan Gizi Masyarakat yang sesuai dengan Rencana Strategis Kementerian Kesehatan tahun 2010-2014 adalah 80\% bayi berusia 0-6 bulan mendapatkan ASI eksklusif (Minarto, 2011). Sudah banyak penelitian dan survei yang menyatakan manfaat dan keuntungan pemberian ASI 
eksklusif baik bagi ibu, bagi bayi, juga bagi keluarga dan masyarakat, namun ironisnya belum banyak penelitian yang membahas cakupan praktik pemberian ASI eksklusif serta Inisiasi Menyusui Dini (IMD). Tujuan studi ini adalah untuk mencari upaya peningkatan cakupan ASI eksklusif dan Inisiasi Menyusu Dini (IMD).

\section{METODE}

Jenis penelitian adalah penelitian deskriptif kualitatif untuk mencari upaya peningkatan cakupan ASI eksklusif dan Inisiasi Menyusu Dini (IMD). Penelitian dilakukan di tigaPuskesmas di wilayah Kabupaten Bantul dengan kriteria puskesmas yang memiliki tenaga bidan konselor ASI. Informan dalam penelitian ini sebanyak lima orang yaitu kepala puskesmas di wilayah Kabupaten Bantul sebanyak 4 (empat) orang dan Kepala Seksi Gizi Dinas
Kesehatan Kabupaten Bantul. Data yang diambil dalam penelitian ini adalah data primer melalui wawancara mendalam kepada informan kaitannya dengan upayaupaya untuk meningkatkan cakupan ASI eksklusif dan Inisiasi Menyusu Dini (IMD) serta data sekunder melalui telaah dokumen atau kajian literatur terhadap peraturanperaturan yang berkaitan dengan pemberian ASI eksklusif. Analisis data dilakukan dengan menggunakan metode analisis isi.

\section{HASIL DAN PEMBAHASAN}

\section{A. Karakteristik Informan}

Informan dalam penelitian ini adalah tiga Bidan Konselor (BK) di wilayah Kabupaten Bantul dan Kepala Seksi Gizi Dinas Kesehatan Kabupaten Bantul (KS) yang karakteristiknya dapat dilihat pada Tabel 1 berikut ini.

Tabel 1. Karakteristik informan bidan konselor dan kepala seksi gizi dinas kesehatan Kabupaten Bantul.

\begin{tabular}{ccccccc}
\hline No. & $\begin{array}{c}\text { Kode } \\
\text { informan }\end{array}$ & $\begin{array}{c}\text { Umur } \\
\text { (tahun) }\end{array}$ & $\begin{array}{c}\text { Jenis } \\
\text { kelamin }\end{array}$ & Jabatan & Pendidikan & $\begin{array}{c}\text { Lama } \\
\text { menjabat }\end{array}$ \\
\hline 1. & BK-1 & 34 & $\mathrm{P}$ & Bidan & D-III Kebidanan & 1 tahun \\
\hline 2. & BK-2 & 39 & $\mathrm{P}$ & Bidan & D-III Kebidanan & 1 tahun \\
\hline 3. & BK-3 & 28 & $\mathrm{P}$ & Bidan & D-III Kebidanan & 1 tahun \\
\hline 4. & KS & 47 & $\mathrm{P}$ & Kepala seksi gizi & D-IV Gizi & 3 tahun \\
\hline
\end{tabular}

Sebagian besar informan menyatakan bahwa ketersediaan tenaga bidan konselor ASI di seluruh puskesmas masih kurang karena baru terbatas satu orang. Kurangnya ketersediaan tenaga bidan konselor ASI di puskesmas juga diperkuat oleh pernyataan Kasie Gizi Dinas Kesehatan Kabupaten Bantul. Upaya untuk meningkatkan cakupan 
ASI eksklusif yaitu dengan pembinaan Kelompok Pendukung Ibu seperti uamh disampaikan oleh bidan konselor 3 sebagai berikut ini.

"Trus sama kemarin itu memang ada Kelompok Pendukung Ibu... dan saya kan bidan wilayah nah saya disitu pas KP Ibu itu mesti saya sampaikan.. KP Ibu itu prinsipnya hampir sama... tentang ASI eksklusif ya saya sampaikan. Tapi sekarang ini memang KP Ibunya udah loyo... jujur saja sudah loyo ini. Ya seperti itu... nggih. Kalau misalnya mereka itu kan datang dengan keluhan bayinya sakit... trus saya tanya masih ASI eksklusif tha? Itu kadang sudah ada yang saya beri formula...nah itu masih ada...sebagian... nah seperti itu kan kadang saya sisipkan sekalian konselingnya. Tapi kan... mungkin... kalo tentang posisi dan lain secara teknisnya kan sudah berjalan... tinggal memotivasi untuk bisa apa ya? Kembali lagi lah... relaktasi he eh seperti itu" (Info BK-3).

\section{B. Cakupan ASI Eksklusif dan IMD}

Mengacu pada target program pada tahun 2014 sebesar 80\%, maka secara nasional cakupan pemberian ASI eksklusif sebesar 52,3\% belum mencapai target. Menurut provinsi, hanya terdapat satu provinsi yang berhasil mencapai target yaitu Provinsi Nusa Tenggara Barat sebesar 84,7\%. Provinsi Jawa Barat, Papua Barat, dan Sumatera Utara merupakan tiga provinsi dengan capaian terendah (Kementerian Kesehatan, 2015). Cakupan pemberian ASI eksklusif pada bayi 0-6 bulan menurut provinsi di Indonesia selengkapnya ditunjukkan pada Gambar 2 berikut ini. 


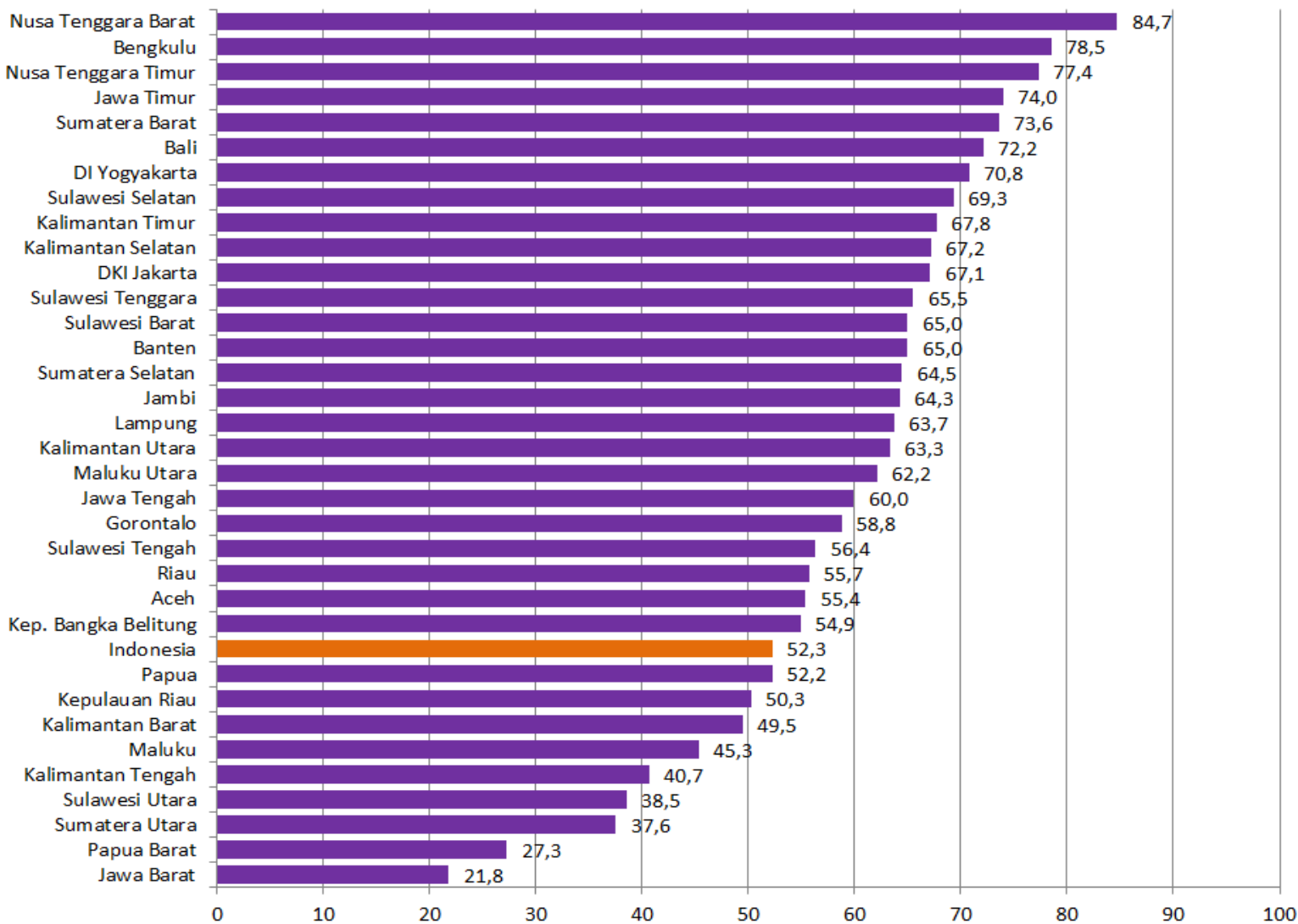

Sumber: Kementerian Kesehatan, 2015

Gambar 2. Cakupan Pemberian ASI eksklusif pada Bayi 0-6 bulan menurut Provinsi Tahun 2014.

Selama ini dukungan yang diberikan baik dari WHO maupun dari pemerintah pusat dan pemerintah daerah terhadap peningkatan pemberian ASI eksklusif sebenarnya telah memadai. Hal ini terbukti dengan adanya rekomendasi dari WHO dan UNICEF (2002) yang dibuat untuk peningkatan cakupan ASI eksklusif, yaitu (1) inisiasi menyusu dini pada satu jam setelah kelahiran, (2) memberikan secara eksklusif, kolostrum kepada bayi dan menghindari makanan/minuman lainnya sebelum pemberian ASI dan makanan lain pada masa awal kehidupan bayi, (3) ASI eksklusif selama 6 bulan pertama kehidupan bayi, (4) memberikan nutrisi makanan tambahan yang hygienis setelah umur 6 bulan. Dukungan politis dari pemerintah antara lain, telah dicanangkannya GNPP-ASI (Gerakan Nasional Peningkatan Penggunaan Air Susu Ibu) pada tahun 1990. Ditetapkannya Keputusan Menteri Kesehatan Republik Indonesia No.450/MENKES/SK/IV/2004 tentang Pemberian ASI secara eksklusif pada bayi di Indonesia, yang memuat sepuluh langkah menuju keberhasilan menyusui diantaranya berisi tentang semua institusi pelayanan kesehatan mempunyai 
kebijakan tertulis mengenai pemberian ASI yang secara berkala dikomunikasikan kepada semua petugas kesehatan, melatih semua petugas kesehatan dengan keterampilan yang diperlukan untuk menerapkan kebijakan tersebut, memberi informasi mengenai manfaat ASI dan menyusui kepada semua ibu hamil, membantu ibu menyusui sedini mungkin dalam waktu setelah lahir sampai satu jam (Siregar, 2004), memberikan ASI kepada bayi tanpa dijadwal dan tidak memberikan dot serta beberapa langkah lainnya.

Pemerintah juga telah menerbitkan Peraturan Pemerintah Republik Indonesia No. 33 Tahun 2012 tentang pemberian Air Susu Ibu eksklusif sebagai jaminan terpenuhinya hak bayi untuk mendapatkan sumber makanan terbaik sejak dilahirkan sampai berusia 6 bulan. Di samping itu, kebijakan ini juga untuk melindungi ibu dalam pemberian ASI eksklusif kepada bayinya. Dalam peraturan tersebut dibahas mengenai Program Inisiasi Menyusu Dini (IMD) dan ASI eksklusif, pengaturan penggunaan susu formula dan produk bayi lainnya, sarana menyusui di tempat kerja dan sarana umum lainnya, dukungan masyarakat, tanggung jawab pemerintah, pemerintah daerah baik provinsi maupun kabupaten/kota dalam serta aturan pendanaannya.

Banyak faktor yang menjadi penyebab rendahnya cakupan Inisiasi Menyusu Dini dan ASI eksklusif di masyarakat. Menurut Siregar (2004), berbagai alasan dikemukakan oleh ibu-ibu yang tidak memberikan ASI secara eksklusif kepada bayinya, antara lain adalah ibu merasa produksi ASI kurang, kesulitan bayi dalam menghisap, ibu bekerja, keinginan untuk disebut modern dan pengaruh iklan/promosi pengganti ASI (Roesli, 2005). Menciptakan kebiasaan pemberian ASI yang baik sejak menit pertama bayi baru lahir sangat penting untuk kesehatan bayi dan keberhasilan pemberian ASI itu sendiri. Menyusui yang paling mudah dan sukses dilakukan adalah bila si ibu sendiri sudah siap fisik dan mentalnya untuk melahirkan dan menyusui, serta bila ibu mendapat informasi, dukungan, dan merasa yakin akan kemampuannya untuk merawat bayinya sendiri. Selain itu keberhasilan ibu menyusui juga harus didukung oleh suami, keluarga, petugas kesehatan dan masyarakat.

Dinas Kesehatan Kota Yogyakarta melalui Puskesmas yang berada di wilayah kerjanya telah melaksanakan program ASI eksklusif begitu juga di setiap rumah sakit swasta maupun negeri. Tetapi ternyata 
prgogram ini belum mampu memberikan hasil yang maksimal terhadap peningkatan cakupan ASI eksklusif. Diperburuk lagi dengan maraknya promosi dan penjualan susu formula serta mudahnya masyarakat dalam memperoleh susu formula di pasaran. Kondisi ini terutama terjadi dikarenakan ibu sudah harus kembali bekerja dan sebagai pengganti ASI maka bayi diberikan susu formula. Seringkali saat seorang ibu kembali bekerja di luar rumah, ibu mengeluhkan kesulitannya untuk tetap memberikan ASI eksklusif dikarenakan jauhnya jarak rumah dengan tempat kerja, tidak bisa memerah ASI di tempat kerja karena tidak ada ruang yang nyaman serta fasilitas untuk menyimpan ASI sampai dengan jam pulang kerja. Padahal saat ini, jumlah ibu yang bekerja semakin meningkat termasuk pada keluarga yang golongan menengah ke bawah karena alasan perekonomian yang kurang.

\section{Upaya Peningkatan Cakupan ASI Eksklusif dan IMD}

\section{Pembinaan Kelompok Pendukung Ibu (KP Ibu)}

Kelompok pendukung adalah kumpulan dari beberapa orang yang mengalami situasi yang sama atau memiliki tujuan yang sama, yang bertemu secara rutin untuk saling menceritakan kesulitan, keberhasilan, informasi dan ide berkaitan dengan situasi yang dihadapi atau upaya mencapai tujuan yang diinginkan. Pertemuan kelompok pendukung dilaksanakan dalam suasana bersahabat, nyaman, saling mempercayai dan menghargai. Melalui pertemuan-pertemuan tersebut, peserta sebuah Kelompok Pendukung dapat saling memberi dan menerima dukungan, baik berupa dukungan teknis, moral maupun emosional untuk sukses mengatasi situasi yang dihadapi atau mencapai tujuan yang diinginkan. Kelompok Pendukung Ibu (KP Ibu) secara khusus diselenggarakan untuk para ibu yang ingin berhasil melaksanakan pemberian air susu ibu secara optimal, yang meliputi inisiasi menyusu dini, ASI eksklusif 6 bulan, dan meneruskan pemberian ASI hingga dua tahun atau lebih dengan makanan pendamping yang bergizi. Kelompok Pendukung Ibu (KP Ibu) merupakan kelompok sebaya yang beranggotakan 6-12 ibu hamil dan ibu bayi bawah dua tahun yang bertemu secara rutin 2 minggu sekali atau setidaknya sebulan sekali termasuk kunjungan rumah untuk saling bertukar pengalaman, berdiskusi dan saling memberi dukungan terkait kesehatan ibu dan anak 
khususnya seputar kehamilan, menyusui dan gizi, dipandu/difasilitasi oleh motivator.

Peserta KP Ibu diutamakan ibu hamil serta ibu ibu yang memiliki bayi usia 0-6 bulan. Walaupun demikian, kelompok ini terbuka untuk orang orang lain yang memiliki minat yang sama. Suami atau anggota keluarga lain dari seorang ibu hamil/menyusui, seorang perempuan yang belum hamil tapi sudah berkeinginan untuk menyusui bayinya suatu saat, atau tenaga kesehatan yang ingin belajar dari dan berbagi informasi dengan para ibu hamil/menyusui dapat dilibatkan dalam pertemuan KP Ibu. Diskusi di pertemuan KP Ibu diutamakan pada isu seputar ASI dan menyusui. Walaupun demikian, bila diskusi berkembang dengan baik tidak tertutup kemungkinan untuk mencakup isu isu lain yang berhubungan dengan situasi peserta KP Ibu, misalnya perawatan ibu pada masa kehamilan, proses persalinan dan pemulihan pasca persalinan, pemberian makanan tambahan pada anak dan lain lain (Karuniawati, 2012).

Kelompok Pendukung Ibu perlu dibentuk di tengah masyarakat dengan memberdayakan masyarakat itu sendiri khususnya para ibu dengan didampingi oleh motivator dari tenaga kesehatan. Dengan saling bertukar informasi dan mendukung satu sama lain diharapkan ibu dapat terus meningkatkan pengetahuannya dan termotivasi untuk memberikan ASI eksklusif. Pembinaan yang baik oleh Puskesmas akan menjadikan kelompok ini bisa terus berkembang dan menarik lebih banyak ibu untuk bergabung di dalamnya. Kegiatan konseling ASI di puskesmas belum berjalan dengan optimal, dilihat dari pelaksanaan yang tidak sesuai dengan langkah keterampilan konseling ASI, upaya sosialisasi belum maksimal, ketersediaan sumber daya manusia dan sarana prasarana yang belum mencukupi (Santi et al, 2015).

\section{Sosialisasi PP No. 33 Tahun 2012}

Pada akhir Maret 2012, pemerintah telah mengeluarkan Peraturan Pemerintah No. 33 tahun 2012 untuk melaksanakan keetentuan Pasal 129 ayat (2) UndangUndang No.36 tahun 2009 tentang Kesehatan. PP ini mengatur Pemberian ASI eksklusif yang menjamin pemenuhan hak bayi untuk mendapatkan ASI eksklusif sejak dilahirkan sampai berusia 6 (enam) bulan dan perlindungan kepada ibu dalam memberikan ASI eksklusif kepada bayi serta meningkatkan peran dan dukungan keluarga, masyarakat, pemerintah daerah dan pemerintah terhadap pemberian ASI eksklusif. 
Bab IV (Pasal 15-29) menjelaskan tentang penggunaan susu formula bayi dan produk bayi lainnya. Pemberian susu formula diperbolehkan pada kondisi dimana pemberian ASI eksklusif tidak dimungkinkan berdasarkan pertimbangan tertentu yaitu indikasi medis, ibu tidak ada dan ibu terpisah dari bayi. Setiap tenaga kesehatan dilarang memberikan susu formula bayi dan/atau produk bayi lainnya yang dapat menghambat pemberian ASI eksklusif kecuali dalam hal khusus yang diperbolehkan. Penyelenggara fasilitas pelayanan kesehatan juga dilarang menerima dan/atau mempromosikan susu formula. Begitu juga dengan distributor susu formula dilarang melakukan kegiatan yang menghambat program pemberian ASI eksklusif termasuk diantaranya dengan menggunakan tenaga kesehatan untuk memberikan informasi tentang susu formula kepada masyarakat. Diatur juga mengenai sanksi administratif terhadap tenaga kesehatan, penyelenggara fasilitas pelayanan kesehatan, pihak-pihak terkait termasuk produsen serta distributor susu formula yang tidak melaksanakan ketentuan yang telah diatur. Peraturan Pemerintah ini juga mengatur tentang perlunya tempat kerja dan tempat sarana umum mendukung program ASI eksklusif dan ini diatur pada Bab V
(Pasal 30-36). Setiap tempat kerja dan tempat sarana umum seperti fasilitas pelayanan kesehatan, hotel dan penginapan, tempat rekreasi,terminal angkutan darat, stasiun kereta api, bandara, pelabuhan, pusat perbelanjaan, gedung olahraga, lokasi penampungan pengungsi dan tempat umum lainnya harus menyediakan fasilitas khusus untuk memudahkan ibu menyusui dan/atau memerah ASI yaitu ruang untuk tempat ibu menyusui bayinya atau memerah ASI (ruang ASI). Pengurus tempat kerja juga diwajibkan memberi kesempatan kepada ibu yang bekerja untuk memberikan ASI kepada bayi atau memerah ASI selama waktu kerja di tempat kerja serta membuat peraturan internal yang mendukung keberhasilan program pemberian ASI eksklusif.

Peraturan Pemerintah No. 33 tahun 2012 sangat membantu untuk mendukung program ASI eksklusif tetapi masih belum banyak pihak yang mengetahui tentang hak tersebut. Perlu juga dibuat Peraturan Gubernur dan perda khusus untuk mendukung PP tersebut sehingga mempunyai kekuatan hukum. Aprillia (2009) menyimpulkan bahwa kebijakan sangat berpengaruh terhadap pelaksanaan program IMD dan ASI eksklusif, selain juga perlu adanya petunjuk pelaksanaan (juklak), petunjuk teknis (juknis) serta protap agar 
bisa mengajukan anggaran serta sosialisasi tentang hal tersebut. Sosialisasi diperlukan agar setiap pihak yang terkait dengan program IMD dan ASI eksklusif mengetahui, mematuhi dan melaksanakannya. Dinas Kesehatan juga dapat melaksanakan ketentuan yang telah ditetapkan tersebut dengan menerapkan sanksi kepada pihak yang melanggar. Selama peraturan pemerintah ini belum disosialisasikan tentu akan sulit untuk memberlakukan sanksi dan upaya meningkatkan cakupan ASI eksklusif menjadi terhambat.

\section{Konselor ASI}

Konselor ASI adalah orang yang dibekali keterampilan untuk membantu ibu memutuskan apa yang terbaik untuknya dan menumbuhkan kepercayaan diri ibu dalam memberikan ASI kepada bayi (Roesli, 2005). Konselor ASI dipilih dari tenaga kesehatan yang kemudian mendapatkan pelatihan khusus konseling menyusui dengan jumlah jam pelatihan yang telah distandarkan oleh badan kesehatan dunia (World Health Association) yaitu 40 jam. Melalui pelatihan ini setiap calon konselor belajar tentang ASI dan segala faktor yang terkait dengan pemberian ASI baik secara medis/teknis, sosial budaya. Para konselor yang sudah terlatih ini dapat memberikan pelayanan konseling bagi setiap ibu mulai dari masa kehamilan, mendampingi saat persalinan untuk membantu dan mendukung proses IMD serta selanjutnya selama ibu menyusui anaknya karena para konselor selain dapat ditemui langsung juga dapat dihubungi melalui telepon ataupun sms (short message system) kapan saja ibu membutuhkan.

Provinsi Daerah Istimewa Yogyakarta telah mengadakan pelatihan konselor ASI bagi tenaga kesehatan yang bekerja di Puskemas dengan pelaksanaan pelatihan diserahkan kepada tiap-tiap Dinas Kesehatan Kabupaten/Kota. Untuk Kota Yogyakarta, pelatihan sudah dimulai tahun 2009 dan terus berlanjut sehingga saat ini semua Puskesmas di wilayah Kota Yogyakarta sudah memiliki tenaga konselor ASI. Bidan konselor ASI yang bekerja di Puskesmas Perawatan mempunyai tugas pokok dan tugas tambahan yang sangat kompleks sehingga tidak jarang mengalami kesulitan untuk melaksanakan setiap tugasnya dengan baik dan berdampak terhadap kinerjanya yang tidak maksimal (Santi, 2014).

Kehadiran konselor ASI diharapkan akan dapat mengurangi permasalahan tentang rendahnya dukungan tenaga kesehatan dalam hal pemberian ASI 
eksklusif. Dengan adanya dukungan, para ibu akan meningkat kepercayaan dirinya dan akan lebih termotivasi untuk terus memberikan ASI. Hasil penelitian Albernaz et al (2003) di Brazil mendapatkan kesimpulan bahwa dukungan konselor ASI dapat memperlambat masa penyapihan terhadap bayi yang disusui. Ini tentunya akan sangat bermanfaat untuk meningkatkan cakupan ASI eksklusif karena ibu-ibu akan lebih lama waktu untuk menyusui bayinya. Perilaku pelaksanaan Inisiasi Menyusu Dini (IMD) dan pemberian ASI eksklusif baik oleh ibu maupun petugas kesehatan terutama bidan, semuanya sangat dipengaruhi terutama oleh faktor sikap, motivasi, maupun pengetahuan, baik sikap, motivasi, dan pengetahuan ibu, maupun petugas kesehatan khususnya bidan (Hector et al, 2005).

\section{SIMPULAN DAN SARAN}

Upaya untuk mengatasi rendahnya cakupan ASI eksklusif di Indonesia adalah dengan memberdayakan masyarakat melalui Kelompok Pendukung Ibu, mensosialisasikan Peraturan Pemerintah No. 33 tahun 2012 tentang pemberian ASI eksklusif dan menyediakan tenaga konselor ASI. Strategi yang dapat dilakukan oleh Dinas Kesehatan yaitu menyelenggarakan pelatihan konselor ASI secara berkala untuk meningkatkan jumlah konselor ASI, melakukan pembinaan, monitoring, evaluasi pelaksanaan kegiatan Kelompok Pendukung Ibu dengan melibatkan Puskesmas yang tersebar di wilayah kerjanya, melakukan kerjasama dengan institusi pendidikan, perusahaan-perusahaan, dan tempat-tempat fasilitas umum dalam upaya melaksanakan ketentuan yang sudah ditetapkan oleh PP No. 33 tahun 2012 serta memberikan reward dan punishment terhadap tenaga kesehatan, fasilitas pelayanan kesehatan yang diketahui melakukan pelanggaran atau menghambat program IMD dan ASI eksklusif.

\section{DAFTAR PUSTAKA}

Badan Penelitian dan Pengembangan Kesehatan Kemenkes RI, 2010. Riset Kesehatan Dasar 2010. Jakarta: Kementerian Kesehatan RI.

Edmond K.M., Zandoh C., Quigley M.A., Amenga-Etego S., Owusu-Agyei S., and Kirkwood B.R. 2006. Delayed breastfeeding initiation increases risk of neonatal mortality. Journal Pediatrics, 117 (3): 380-386.

Hector D., King L., and Webb K. 2005. Factors affecting breastfeeding practices: Applying a conceptual framework. NSW Public Health Bull, 16 (3-4): 52-55.

Karuniawati, N.S. 2012. KP Ibu, Sarana Efektif Peningkatan Cakupan ASI 
Eksklusif. [Cited 2012 May 5]. Available from: http://www.dinkes.kulonprogokab.go.i $\mathrm{d} /$ ?pilih=news\&mod=yes\&aksi=lihat \&id $=105$.

Kementerian Hukum dan Hak Asasi Manusia, Lembaran Negara Republik Indonesia. 2012. Peraturan Pemerintah No. 33 Tahun 2012 tentang Pemberian ASI Eksklusif. Jakarta: Kementerian Hukum dan Hak Asasi Manusia.

Kementerian Kesehatan Republik Indonesia. 2004. Keputusan Menteri Kesehatan Republik Indonesia No. 450/MENKES/SK/IV/2004 tentang Pemberian ASI secara eksklusif pada bayi di Indonesia.

Kementerian Kesehatan Republik Indonesia. 2015. Profil Kesehatan Indonesia Tahun 2014. Jakarta: Sekretariat Jenderal Kementerian Kesehatan.

Minarto. 2011. Rencana Aksi Pembinaan Gizi Masyarakat (RAPGM) Tahun 2010-2014. [Cited 2012 May 6]. Available from: http://www.gizikia.depkes.go.id/archiv es/658.

Roesli, U. 2005. Mengenal ASI Eksklusif seri 1. PT Pustaka Pembangunan Swadaya Nusantara.
Roesli, U. 2008. Inisiasi Menyusu Dini plus ASI Eksklusif. Cet-1. Jakarta: Pustaka Bunda.

Santi, M.Y. 2014. Implementasi Kebijakan Pemberian Air Susu Ibu Eksklusif Melalui Konseling oleh Bidan Konselor. Kesmas Jurnal Kesehatan Masyarakat Nasional, 8 (8): 346-352.

Santi, M.Y., Margawati, A. and Mawarni, A. 2015. Faktor Komunikasi dan Ketersediaan Sumber Daya dalam Implementasi Konseling Air Susu Ibu oleh Bidan Konselor ASI. Jurnal Kesmas Indonesia, 7 (3): 190-208.

Siregar, A. 2004. Pemberian ASI Eksklusif dan Faktor-faktor yang mempengaruhinya. Medan: Fakultas Kesehatan Masyarakat Universitas Sumatra Utara.

Tasya, A. 2011. Hak Ibu Menyusui di Indonesia. [Cited 2012 April 14]. Available from: http://aimiasi.org/2011/08/hak-ibu-menyusui-diindonesia/comment-page1/\#comment-33032

World Health Organization, 2007. Community-based Strategies for Breastfeeding Promotion and Support in Developing Countries. Geneva. 